\title{
Work safety interventions and threat complexity - A formative investigation into why farmers do not act safely
}

\author{
Catharina Elisabeth Alwall Svennefelt ${ }^{1, A-F} \oplus$, Erik Hunter ${ }^{1, A, C-F} \oplus$, Anna Maria Palsdottir ${ }^{1, D-F} \oplus$ \\ ${ }^{1}$ Department of Work Science, Business Economics \& Environmental Psychology, Alnarp, Sweden \\ A - Research concept and design, B - Collection and/or assembly of data, C - Data analysis and interpretation, \\ $D$ - Writing the article, E - Critical revision of the article, F- Final approval of article
}

Alwall Svennefelt CE, Hunter E, Palsdottir AM. Work safety interventions and threat complexity - A formative investigation into why farmers do not act safely. Ann Agric Environ Med. 2019; 26(2): 280-289. doi: 10.26444/aaem/105798

\section{Abstract}

Introduction. Fear appeals are a common tactic used in work safety interventions to motivate farmers to adopt safer behaviours. They begin by introducing a threat, followed by information on how to remove the threat. However, fear appeals tend to be ineffective when developed without a firm grasp of the cognitive processes underlying behavioural change. Although previous research on farm safety interventions have investigated fear appeals, they have focused on very narrow threats and behaviours, such as tractor or cow safety, while others have studied the threats but not the cognitive processing. Consequently, not enough is known about the range of threats that evoke fear, how farmers behave when under threat, or their general cognitive beliefs regarding self-efficacy, response cost and response efficacy. In In this study, 23 Swedish Farmers were interviewed and participated in a work safety intervention to identify the range of threats farmers perceive, and actions taken to remove those threats.

Materials and method. The extended parallel processing model was used to gain insights into how farmers cognitively processed threats and their subsequent behaviour. Interestingly, it was found that farmers were more fearful of work safety threats related to family members and employees-yet the actions they took to reduce threats were mostly personal in nature. To help explain this finding, a typology of threat complexity was developed by the authors.

Results. It was found that simple, common, and direct threats to safety tended to lead to adaptive, threat-reducing behaviours, whereas complex, general, or indirect threats promoted more maladaptive behaviours that reduced fear, but not the threats.

\section{Key words}

agriculture, extended parallel processing model, fear appeals, occupational injuries, formative research, Safe Farmers Common Sense

\section{INTRODUCTION}

It is well known that agricultural work is dangerous $[1,2,3,4]$ and that the key to reducing occupational injury, illness and death, starts with identifying safety risks, and then taking measures to remove or mitigate them [5]. Over the years, numerous interventions attempting to inform about and reduce occupational safety risk have taken place on farms, but with marginal effectiveness $[5,6,7,8]$. In general, farmers are aware of the most common work safety risks $[1,9,10,11]$, yet still struggle to translate this awareness into behaviours that remove or mitigate them. One explanation for this risk awareness - the risk prevention behaviour gap, may be a lack of farmers' motivation. However, most agricultural work safety interventions recognize (at least implicitly) the need to motivate farmers in order to influence safer work behaviours $[12,13,14,15]$.

Fear is a powerful emotion that can be used to manipulate behaviours $[16,17,18]$, and there is evidence indicating it is the most common motivational approach used in interventions to influence farm safety behaviour $[12,14]$. Therefore, awareness and motivation alone do not explain why many farmers continue to expose themselves to risks that lead to occupational injury, illness and death.

Address for correspondence: Catharina Elisabeth Alwall Svennefelt, Departement of Work Science, Business Economics \& Environmental Psychology

E-mail: catharina.alwall@slu.se

Received: 28.10.2018; accepted: 14.03.2019; first published: 17.04.2019
The influence of fear on subsequent behaviours depends on interactions with other cognitive factors, such as perceived vulnerability, severity, self-efficacy, response efficacy, and response cost $[19,20]$. For example, the threats used to arouse fear must be perceived by the farmer as likely to occur and severe in their nature. If they are not, fear is not aroused and the farmer will be less motivated to alter his behaviour. Similarly, farmers must feel capable of carrying out the risk reducing behaviour, and that by doing so it will be effective in reducing the threat. At the same time, the cost of changing the behaviour needs to outweigh the risks. Because of this, fear appeals can actually promote maladaptive behaviours (e.g. individuals may end up increasing the very behaviours targeted for extinction) when fear is high but belief in the behaviour is low. This may also take the form of individuals denying, minimizing or avoiding thinking about threats [21] or a tendency for individuals to rebel against the messages (i.e. in this context information about threats) that restrict their perceived freedom [22]. For this reason, work safety interventions and the fear appeals they use should be theory driven and based on an empirical understanding of the factors that influence individual behaviour.

Although previous research on farm safety interventions have investigated fear appeals, they have focused on narrow threats and behaviours, such as tractor $[9,23]$ or cow safety [24]. Others have studied threats but not cognitive processing $[25,26,27,28]$. Consequently, little is known about the range of threats that evoke fear in farmers and their general 
cognitive beliefs regarding self-efficacy, response cost and response efficacy. Fear appeals tend to be ineffective when developed without a firm understanding of the cognitive processes underlying behavioural change $[29,30]$. It is no surprise that farm work safety intervention programmes based on educating and informing have been criticized for not demonstrably improving work safety [7, 30, 31]. Alwall Svennefelt et al., [12] argue that these criticisms are misplaced and that the problem with educating and informing lies not primarily in the tool, but rather in its implementation.

Through formative research $[32,33]$, the authors argue that a deeper understanding of the threats and cognitive factors that mediate and moderate behaviour change can be attained and used to more effectively promote safe working behaviours on farms. Consequently, the aim of this study is to develop a deeper understanding of the cognitive mediating process related to farmers, fear and safe working behaviours. More specifically, the following three research questions are address:

1. Which threats to safety are perceived by and arouse fear in farmers?

2. Which fear-reducing, work safety strategies do farmers perceive to be effective, manageable, and cost-effective in reducing threats to safety?

3. What actions do farmers take to reduce perceived work safety dangers or their fear of them through maladaptive behaviours and why?

\section{CONCEPTUAL FRAMEWORK}

Connection between work safety interventions, fear and safe behaviour. The relationship between fear as a motivator of behavioural change has been studied since the 1950s [34]. Early on, fear was conceptualized as a learned response to threats and motivator of behaviour [35]. The mechanism behind behavioural change was the unpleasant emotional state (i.e. fear) that threats evoked and the desire to remove cognitive uneasiness stimulated by fear. When promoting, e.g. healthy behaviours, it was assumed that arousing the emotional state of fear was necessary for effective fear appeals [36]. Leventhal [37] pointed out in his dual-process model that some individuals react cognitively to threats and consider actions to avoid them (referred to as a danger control process). Others react emotionally and control their fear (a.k.a., a fear control process) by way of denying the existence of a threat and avoiding thinking about it [38].

Roger's $[19,20]$ Protection Motivation Theory (PMT) was introduced to understand the danger control process and explain protection motivation. The premise behind PMT is that there are cognitive mediating processes that mediate the relationship between fear appeals, e.g. a television commercial with the message: 'wear your seatbelt or you could die in a car accident') and behaviour, e.g. individual starts to wear their seatbelt to remove the fear of dying in a car accident.

The cognitive mediating process includes threat severity and vulnerability of occurrence, which evokes fear. Efficacy is a combination of self-efficacy - the ability and confidence one has in performing a recommended action [39] and response efficacy - the ability of the action to reduce the threat. When perceived threat severity and vulnerability are high enough (arousing fear), and perceived efficacy is also high, the model predicts protective motivation. However, when the intrinsic or extrinsic rewards of not following a recommended behaviour are higher than the fear that is aroused, or if the cost of taking action is greater than the perceived efficacy, the model predicts maladaptive behaviour.

Witte's [6] Extended Parallel Process Model (EPPM) builds on Leventhal's $[37,40]$ dual-process model and incorporates the danger control process found in PMT. EPPM attempts to explain how fear and efficacy interact and better understand how people deal with their fear by denying or defensively avoiding threats [6] (Fig. 1).

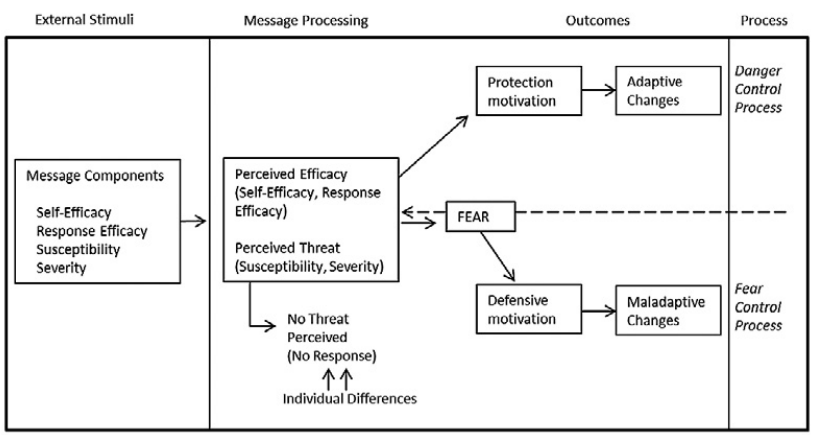

Figure 1. Components of the extended parallel process model (EPPM) [6]

The extended parallel process model (Fig. 1) was developed to explain three processes and behavioural responses to fear: non-responses, danger control responses, and fear control responses [41]. The model predicts how individuals will respond to fear, depending on the perceived threat (comprised of susceptibility and severity) and perceived efficacy (comprised of self-efficacy and response efficacy).

On the left side of the EPPMs model there are different message components, i.e. external stimuli that influence cognitive processing. PMT also addresses these external stimuli and message components and are one of many sources of potentially influential information. This includes, e.g. prior experience and observational learning. EPPM proposes that responses to fear appeal messages depend solely on whether the message increases perceptions of a threat - its severity and vulnerability. The type of action that occurs afterwards (see message processing in the middle of the model in Figure 1) is dependent upon evaluations of the perceived efficacy (self-efficacy and response efficacy) in reducing the threat: 'If a threat is perceived, the fear appeal message will be successful in motivating people to engage in the recommended protective behaviours if it successfully increases people's confidence that they are capable of engaging in the recommended behaviour, and this behaviour is an effective means of avoiding the threat' [41].

Witte [42] clarified what happens if there is no information regarding the efficacy of a recommended response by saying that individuals will rely on their past experiences and beliefs to appraise perceived efficacy. Ramal's [43] risk perception attitude framework takes this one step further and argues that risk perceptions are a property of the individual and not a property of the message [43]. In the absence of a fear appeal, threat/risk/efficacy perceptions are based on previously learned experiences.

Given previous experiences and perceptions of threats relating to the efficacy of responses available, three difference processes are expected by the EPPM: 1) Non-responses, 2) Danger control responses, and 3) Fear control responses. 
Non-response occurs when no threat is perceived since fear is not activated. If a threat is perceived that leads to fear, a second process of efficacy appraisal occurs. When fear and efficacy towards a specific action are high enough, danger control responses are expected. However, when fear is high and efficacy is low, fear control responses are predicted. When fear control is activated, individuals will attempt to reduce their fear by denying, minimizing and avoiding thinking about the threat [21], or rebelling against messages that restrict their perceived freedom [22].

The EPPM has been used to model a wide range of health $[44,45,46,47,48,49,50]$ and other behaviours believed to be motivated by fear $[51,52,53,54]$, including work safety behaviours on farms $[23,45]$. Consequently, the authors propose that EPPM is still a suitable framework to use when studying work safety interventions, and consequently adopted it to investigate the research questions in this study.

\section{MATERIALS AND METHOD}

The study was conducted as a formative evaluation [32] based on interviews with 23 Swedish farmers [55]. Formative evaluation enabled a deeper and more thorough understanding of the farmers' attitudes towards safety procedures and accidents that can be used to more effectively design educational interventions, thus targeting farmers' safe working behaviours.

Preparatory phase $\&$ data selection. Prior to the actual data collection, pilot Interviews were conducted [56], with six randomly-selected farmers from Scania, the most southerly province of Sweden, who participated in the campaign 'Safe Farmers Common Sense'. The participants were selected from a list provided by the Swedish Farmers' Association (LRF). They were contacted in the order they were listed, i.e. the first name on the list was contacted and invited to take part in the study. If the farmer agreed, the next name of the list was contacted. If that farmer declined to participate, the following name on the list was contacted, and so on until six persons agreed to participate in the pilot study.

The pilot interviews were useful for refining the language used in interviews, and to familiarize the interviewees with the technical language and colloquialisms used by farmers when discussing work-related safety issues. Insights from the pilot interviews also helped to create the semi-structured interview guide [55] used for the main data collection. After talking to six farmers, it was assessed that there was sufficient awareness of how they reasoned and understood the theoretical terms used.

Following the pilot interviews, a further 23 farmers (also from Southern Sweden) were chosen for interviews. All of them had participated the previous year in the national safety campaign Safe Farmers Common Sense (SFSC). During SFSC, these farmers were exposed to a wide range of information on safety threats, as well as different strategies for reducing or mitigating threats. By following-up on the farmers one year later, it was possible to discuss with them the threats they perceived in their environment, and to reflect on the work safety changes which had, or had not taken place. While SFSC was implemented across Sweden, only farmers in Southern Sweden were invited to atteend interviews because of their geographical concentration. Also, all of the main agricultural production activities are represented in Scania. This offered a good opportunity to access a group of participants active in a variety of farming activities with a wide diversity in demographic and production characteristics.

The farmers were contacted by telephone and informed about the project, how they were selected, and invited to participate. They were also informed that all information would be treated confidentially and that they could cancel participation at any time [56]. Of the 31 farmers contacted, 23 agreed to participate in the interviews.

The 23 farmers ( 5 women and 18 men) ranged in age from 34-74 years. The majority were engaged in plant breeding, mostly in combination with pig or beef production, fewer with horses and hens. Most farmers worked full-time on the farm, some of them had children, a few had employees, and some had help from older relatives (e.g. older father). Each interview began with an introduction to the project, what the data would be used for, and in which form the results would be presented. The participants were reminded that the study was voluntary and anonymous, and that they could withdraw their participation at any time without incurring any consequences. The participants were also asked for their permission to record the interviews [56] which lasted from 1.5 - 2 hours.

In order to address issues related to the risks involved in the work and experiences of the safety campaign 'Safe Farmers Common Sense', each farmer was asked to describe his/her farm in terms of production, occupancy, organization and daily operations. The interview questions were structured around several themes, including:

1) concerns for work safety in the context of production;

2) occupancy;

3) organization;

4) daily operations;

5) the barriers they perceived in improving work safety conditions on their farm;

6) what steps they have taken to improve work safety.

These themes corresponded to the External Parallel Process Model (EPPM) threat appraisal, coping appraisal, and adaptive or maladaptive behaviour. Several additional themes were covered in the interviews, among them the role of advisors in influencing participant behaviour, and other inspiration to address work safety.

Theoretic thematic analysis. Theory-driven thematic analysis [57] and selective sorting based on EPPM themes were employed to analyze the above questions. All interviews were recorded and transcribed. Each transcript was read numerous times to identify and obtain an overall understanding of relevant statements fitting the authors' theoretical model. The transcripts were coded, based on cognitive mediating components of the EPPM (perceived severity, perceived susceptibility, self-efficacy, response efficacy and fear) as follows:

- data was coded as fear when topics revolving around something bad happening at work were discussed (e.g. children, elderly, foreign labor force, increased risk of falling due to advancing old age, or lack of sufficient knowledge in animal management);

- as perceived severity when farmers shared their perceptions of how bad (i.e. the degree) it would be if the employees were injured, the elderly did not listen, or the risk of the children playing around tractors or straw bales; 
- as perceived susceptibility when farmers reflected on the likelihood that a threat or something bad was going to happen, employees or children getting injured;

- as self-efficacy when farmers perceptions of economy, time and/or health reasons prevent them from performing work satisfactorily;

- response efficacy where, e.g. farmers share their beliefs about whether improving work safety will make working on the farm safer.

The initial coding was performed by the author who conducted the interviews. This was evaluated by the coauthors to avoid single author bias, and ensure agreement in data interpretation [58].

\section{RESULTS}

The results are presented according to the EPPM themes and answering the three main questions proposed for this study. The first theme reflects on farmers' Perceived threats. The second theme on farmers' Perceptions of efficacy and costs, and the third and last reflects on Continued risky and maladaptive behaviours.

Perceived threats - farmers. Most of the farmers interviewed reasoned similarly in the belief that farming is a dangerous business, or as one farmer explained: 'It is always in the back of your mind, there is no question about it, farm work is dangerous'. When asked specifically to describe the threats they thought were dangerous, most of the responses could be categorized based on whether they were personal or impersonal, and whether the threats were direct or indirect (Tab. 1). Participants also discussed their fears, but they were not always aware or able to articulate the specific threat that caused the fear. Some examples of this are discuss below, as well as the direct/indirect and personal/impersonal threats that emerged from the interviews.

Stress was discussed repeatedly in the interviews; however, only as a consequence and not as a threat per se. The farmers stated that farming is physically demanding, and because of long working hours, they experience a lack of sleep and attributed these factors to increased stress. Stress was also associated temporally with production intensity that varies throughout the year: 'When the harvest comes, everyone on the farm works 16-17 hours a day, that's when you're really afraid that something's going to happen'. Even though stress was attributed to the working conditions on the farm, neither the conditions perceived to cause stress nor stress itself were seen as direct threats. Rather, the physical nature of the job led to back pain, and lack of sleep led to increased accidents when operating machinery. In turn, back pain and tiredness were perceived as relevant and serious threats. In addition to back pain and tiredness, farmers viewed hitch hooks, power transmissions and difficulty in breathing (i.e. reduced lung capacity) as factors to take into account. As such, farmers expressed vulnerability towards threats that were immediate - direct, and threats that may affect them over time - indirect.

The types of threats that the farmers perceived were not limited to those that affected themselves (i.e. personal as opposed to impersonal). For example, several farmers mentioned that they preferred to handle dangerous tasks themselves than to let an employee carry them out. One farmer stated: 'When you have employees, you also have enormous responsibility (...) because of that, I don't allow employees to do some of the dangerous jobs'. The risk of employees being injured seemed to be an issue for some farmers in the study. Language barriers and foreign laborers lacking experience were also threats perceived by the farmers. One farmer stated: 'They do not have the animal traditions that we have'. Some farmers expressed concern about their children since the farm is an exciting but dangerous place they use as a playground. In particular, they felt their children were highly vulnerable to serious injury when playing with tractors and machines, and when playing in straw bales and climbing ladders. One farmer expressed this concern by stating: 'What I'm afraid of is that little guy who runs around the farm (...) he climbs when the ladders are set, one day he may be in another place, this is what I'm most afraid of actually.'

Some of the farmers, in particular those whose parents were older and worked on the farm, were concerned because 'they continued to behave and work as they have always done and were difficult to influence.'

Table 1. Examples of perceived threats and their direct or indirect personal or impersonal relevance as described by the farmers

\begin{tabular}{|c|c|c|}
\hline & Indirect & Direct \\
\hline 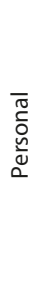 & $\begin{array}{l}\text { - problems breathing } \\
\text { - sleeplessness } \\
\text { - back-pain } \\
\text { - hearing loss \& other long term } \\
\text { health problems } \\
\text { - lawsuits } \\
\text { - regulators shutting down the } \\
\text { farm } \\
\text { - old machinery }\end{array}$ & $\begin{array}{l}\text { - chemical splashes and spills } \\
\text { - heavy machinery } \\
\text { - hitch-hooks and power } \\
\text { transmissions } \\
\text { - maintenance machinery } \\
\text { - tree felling }\end{array}$ \\
\hline 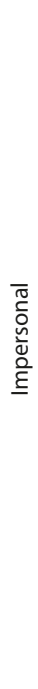 & $\begin{array}{l}\text { - employees not paying attention } \\
\text { or following instructions to } \\
\text { farmers recommendations } \\
\text { may lead to a fine from the } \\
\text { Occupational Safety Authority } \\
\text { - migrants at risk of harming } \\
\text { themselves because they do not } \\
\text { have sufficient animal / language } \\
\text { skills may lead to possible fines } \\
\text { from the Occupational Safety } \\
\text { Authority }\end{array}$ & $\begin{array}{l}\text { - children (and sometimes their } \\
\text { visiting friends) run over by a } \\
\text { tractor, falling from straw bales, } \\
\text { risk of being killed when hiding in } \\
\text { tractor wheels } \\
\text { - migrants are at risk of harming } \\
\text { themselves because they do not } \\
\text { have sufficient animal / language } \\
\text { skills and likely to get seriously } \\
\text { injured. } \\
\text { - elderly on the farm might } \\
\text { get killed due to a decline in } \\
\text { physical endurance, and strength } \\
\text { decreases } \\
\text { - employees who do not } \\
\text { pay attention to farmers } \\
\text { recommendations to take } \\
\text { precautions when dealing with } \\
\text { animals, tractor work, using } \\
\text { protective equipment or similar; } \\
\text { thus, they are likely to get } \\
\text { seriously injured }\end{array}$ \\
\hline
\end{tabular}

Perceptions of efficacy and costs. During the interviews, the farmers were asked whether taking preventative steps to improve safety was effective, and also about perceived barriers towards making work safety improvements. The majority of farmers felt unable to prevent safety risks beding taken on their farm, most often when they were related to other people. In particular, those related to age, employees, children, the elderly, farmer's economic situation and regulatory authorities. 
The farmers believed that ensuring that employees comply with safety procedures is difficult because they had limited influence over their behaviour. The perceived inability to influence employees appears to stem from reliability, insubordination and miscommunication. For example, the farmers who have employees stated that they implored them to follow safe work routines when handling animals and operating heavy machinery. However, their requests were often ignored or misunderstood. One farmer, highlighting an instance of unreliability stated: 'There is a bull in here, so I tell the employee to lock up when they leaving. Sometimes it gets done and sometimes it does not. I can't sit there the whole time and micromanage whether he locks the gate (...) the guy is nice, but I usually have to follow-up and close the gate myself. I can't force him'. The challenge with foreign labourers is not only about reliability in following safety procedures, it is compounded by language barriers that lead to miscommunications in instructions and the ability to explain the importance of following safety procedures.

Farmers with young children understood the importance of creating a safe working environment in which they can play, but expressed frustration and a lack of concrete ideas for achieving such a safe working environment. They appear resigned to the belief that the farm will always be a dangerous, yet captivating place for children to play. The children 'run around when heavy machinery is in operating', and are attracted to play in the most dangerous areas of the farm. The farmers try to mitigate the injury risks by closely supervising their children, but readily admit that over time 'You get blunted, and in the end you don't see if they are around (danger)'.

The ability to manage age-related safety risks differed depending on the age of the farmer. Older farmers recognized that with age their vision, hearing, reaction time and mobility worsened; leading to increased safety risks. However, by accepting their limitations, the older farmers believed they mitigated the safety risks by 'being more careful and slowing down'. Interestingly, the "younger" farmers who had elderly relatives working on the farm saw things differently. They felt that rather than slowing down and taking things easy, the elderly farmers continued to work as they had always in the past. They attempted to reduce risks by talking to their elderly relatives and asking them to limit their working hours, slow down, and in one case, to carry a communication device so they could contact help in case of an emergency. The general consensus was that the elderly relatives flatly refused to acknowledge the age- related increase in injury risks, or listen to advice from their family. One farmer summed up the situation as follows: 'Dad is stubborn, we've told him he's got to have a phone with him, but he refuses to even discuss the issue and just says no (...) he is an old man, over 80 , and it is not possible to teach him anything'.

Farmers who experienced a bleak economic situation tended to operate older, poorly maintained machinery. Although they were aware of the safety risks and need to invest in new machinery, they were unable to do so due to lack of resources. Moreover, the stress created by financial problems meant that they tended to work longer hours to make ends meet, and had little time to carry out routine maintenance on their equipment or engage in other preventative safety behaviours. Under these conditions, it made sense to farmers that managing the risk of finanial failure takes priority over managing the risk of personal injury: 'First of all I have to have time, time to do something preventative and not just prevent acute emergencies... then of course money too ... to change stuff, that's the economic reality, you need to be able to afford all of this... so my machine park is not quite tiptop.'

Adaptive changes to work safety environment and behaviour. Most farmers maintained that safety prevention changes were made to the working environment following the intervention of the FSCS. These included installing seat rails on hay litters, purchasing fire blankets, goggles, eye rinse, mouth or hearing protection against tractor noise. Dressing cabinets were reinforced, worn hitch-hooks replaced, power transmission shafts were fitted with added protection, and ergonomic chairs installed in machines. One farmer emphasized that he became more careful after participating in 'safe farmer common sense' when it came to handling lorries, while another stressed the handling of the thresher. A third farmer related how he became more careful about heavy lifting (through better lifting technique) after sustaining a back injury, while another farmer said that he took more care with silo work by using a protection harness.

For those farmers who expressed concerns for their children, some ad hoc improvements were introduced; for example, one farmer anchored the straw bales, and another secured a tractor wheel to the wall because 'I would always watch the tractor wheel to make sure my kid was not there, but my wife was terrified that he (my child) would sit there while we took a break'.

Interestingly, the threats that farmers feared most in the previous section were those associated with children, the elderly and farm workers (i.e. referred to here as impersonal). However, when the farmers were asked about changes in their work safety environment, most of the changes concerned reducing direct risks to themselves (Tab. 2).

Table 2. Adaptive changes to work safety environment and their direct or indirect personal or impersonal relevance, as described by the farmers.

\begin{tabular}{|c|c|c|}
\hline & Indirect & Direct \\
\hline 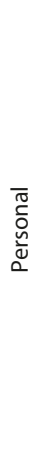 & $\begin{array}{l}\text { - to promote musculoskeletal } \\
\text { disorders adopted safe lifting } \\
\text { techniques } \\
\text { - in order not to suffer from lung } \\
\text { damage or lose consciousness } \\
\text { through carbon dioxide } \\
\text { penetrating the oxygen at silo } \\
\text { work, use protection harness } \\
\text { - because of reduced lung } \\
\text { function, use mouth protection in } \\
\text { the stable } \\
\text { - because of stress in season work, } \\
\text { eat and sleep well } \\
\text { - because of stress in season work, } \\
\text { service machines }\end{array}$ & $\begin{array}{l}\text { - } \text { seat rails on hay litter } \\
\text { - fire blankets } \\
\text { - goggles, eye rinse, mouth } \\
\text { protection or hearing protection } \\
\text { - first aid box } \\
\text { - protective clothing } \\
\text { - dressing cabinets reinforced } \\
\text { - worn hitch hooks replaced } \\
\text { - power transmission shafts fitted } \\
\text { with added protection } \\
\text { - ergonomic seats installed in } \\
\text { machines } \\
\text { - service machines in seasonal } \\
\text { work } \\
\text { - protection harness }\end{array}$ \\
\hline 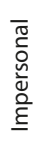 & & $\begin{array}{l}\text { - straw bales anchored to prevent } \\
\text { children falling at play } \\
\text { - tractor wheel secured to a wall to } \\
\text { prevent falling onto the child } \\
\text { - protective equipment }\end{array}$ \\
\hline
\end{tabular}

Continued risky and maladaptive behaviours. Even though most farmers reported adopting some safe work behaviours, many of the perceived threats they mentioned were not reduced or mitigated. Instead, a number of maladaptive behaviours related to defensive avoidance and reactance were identified 
Defensive avoidance, or the denial, minimization or avoidance of information related to threats, surfaced repeatedly in the interviews. For example, one farmer continued to use a broken piston shaft even though he knew it was unsafe. To justify his behaviour he stated that he 'only uses it himself', and rationalizes away the danger by 'reminding himself that he should be careful'. Similarly, another farmer acknowledged that the protective trousers he was using offered inadequate protection: 'I have these protective trousers on me, and I've thought that sometimes I should have more protection'. Instead of reducing the safety risk by purchasing new trousers, he convinced himself that 'I'll just go down to the woods for a few hours, I'll be careful.' Another (female) farmer who was strapped for cash, avoided thinking about the threat by blaming others: 'If only the bank supported us, everything would be different on the farm'. The farmer further expressed frustration by emphasizing that both her husband and her father-in-law were sloppy and careless, despite the fact that there were children in the farm who had suffered an accident a year earlier. The farmer also exhibited a form of psychological reactance when it came to the dangerous animals on the farm. She was fearful of the farm's bull, but she was not prepared to remove it because her daughter wanted her own calf.

The role of the advisor in the "Safe farmer common sense" campaign was to guide farmers to create 'a good and safe work environment' by helping the farmer to get started on learning how to identify the farm's security shortcomings. Instead of following the advice they were given, some farmers provided even clearer evidence of psychological reactance by criticizing the advisor of (risk) information rather than the risk itself. For example, several farmers described the advisor's level of knowledge as 'deficient', and the method of identifying farm threats below expectations. One expressed the desire for more hands on course management, while another wanted better instruction and more efficient time utilization. A third thought higher, formal skills of the advisor were needed. According to some farmers, the advisor should be knowledgeable on the subject and good at raising interest. They should not be nonchalant while at the same time being pernickity. 'The advisor seemed to be lost when it came to logistics (...), and the impression was the advice was not worth five pence.' Another farmer quipped: 'So, a lot of it deals with classic questions about risks and reward trade-offs. Some things get discussed at the inspection, and if it is not a risk, I am prepared to accept that discussion (...) But as with all this, it must feel that it gives something back and that you (the advisor) have a clarity and professionalism when you come out.' These are signs that some farmers seem to control their fears rather than the dangers pointed out by advisors.

Another form of resistance noted among farmers was that they became angry and 'reacted' because they seemed to feel manipulated by the authorities. A farmer stressed that there are too many rules that do not concern the farmers who are most in need of them: 'There are some rules that can be misinterpreted between what is required under Swedish law, and what is general safety advice'. The same farmer continued to refer to regulations and unnecessary costs for the single farmer: 'Then you do a risk analysis. How likely is it that I am fined for not following the rules for things I do not find important (...) we create our own rules for what we experience.'
Finally, several of the farmers simply chose to ignore information and advice given to them by advisors. For example, one farmer said: 'It is important that this is going on and I think it's hugely important for the whole industry (...) but it does not change anything in my life.' Another said: 'There is always a situation for improvement (...) we do not have written routines (...) I think questions (of safety) exist and they emerge naturally in dangerous circumstances.'

\section{ANALYSIS AND SUMMARY OF RESULTS}

This section introduces the typology and continuum of perceived threats that emerged from the obtained data for three reasons (Fig. 2):

1) Using EPPM on qualitative data for anything more than descriptive purposes presents several challenges for researcher due to the multitude of threats, behaviours and cognitive processes occurring within and across participants. To overcome this limitation, some form of data reduction is required to identify and make sense of how factors in EPPM are related.

2) Several patterns emerged from the data where different kinds of threats (or threat typologies) appeared to play an important role on threat appraisals and EPPM factors. Ultimately, the type of threat seemed to have a profound influence on subsequent behaviour.

3) It was recognized that many, if not most, of the perceived farm safety threats that emerged in this study are known to the research community. However, they are scattered across a number of reports and studies [1], and thus far, the authors have not found any attempts to classify perceived threats into typologies. The authors recognize that no typology is empirically correct, but argue that they are useful for conducting future research, and for advisors and farmers attempting to identify threats.

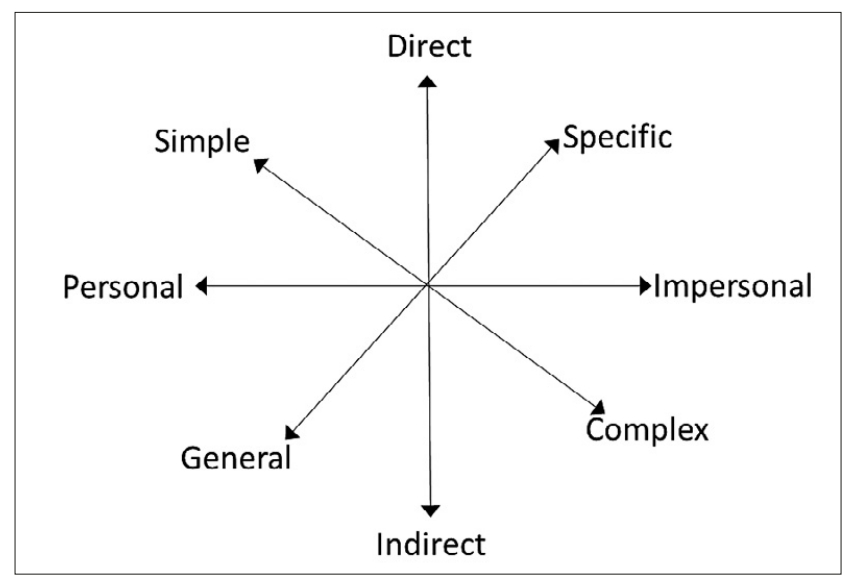

Figure 2. Typology and continuum of farmers perceived threats

Direct and indirect threats relate to the immediacy of the perceived danger. At one end of the continuum, perceived direct threats are those that pose an immediate danger, such as being impaled by a bull, whereas the danger posed by indirect threats are delayed, e.g. loss of hearing due to operating noisy machinery, or breathing problems caused by dusty and dirty working environments. Overall, direct threats were not viewed as being more severe or the individual being more vulnerable; however on the whole, the participants took 
action to prevent direct threats more often than indirect threats.

Threats can also be distinguished by whose safety is at stake. The farmers talked about personal threats to their health and well-being that included back injuries from heavy lifting and hearing loss due to operating noisy machinery (using the authors' typology, noisy machinery is also an indirect threat when viewed in terms of immediacy - see above). Personal threats also include being fined by occupational safety inspectors when farm hands violate rules. At the other end of the continuum, impersonal threats are those involving others whose health and well-being matter to the farmer. Earlier, who the others were was mentioned and found that children and other family members were important, as were farm hands. Interestingly, the farmers tended to view others or impersonal threats as being more likely to occur and more serious.

Distinguishing threats based on their general or specific nature was found to be useful. General threats are those commonly perceived on farms such, as fires and machinery accidents, whereas specific threats pertained to farmers in a specific context. This 'specific context' includes protective equipment when working in silos, or becoming caught in a power transmission shaft, but is not limited to physical threats, such as heavy machinery that could fail and cause injure due to the lack of time or money needed to conduct routine maintenance. While no patterns were detected in how general and specific threats influenced factors in EPPM, it must be emphasized that context seemed to strongly influence the kinds of threats perceived by farmers (e.g. financially distressed farmers stated threats to well-being more so than farmers who were well off).

Finally, large differences we found in threat complexity. This means that many of the threats discussed, such as the threat of fire or hearing loss, had relatively simple causes that farmers understood well. However, there were also a number of 'complex' threats discussed, such as age-related injury and stress. Due to their complexity, farmers were not always able to pinpoint or fully account for what caused the threat. In the case of stress, farmers viewed it as an actionbarrier, but not as a threat in itself in itself. Overall, when threats were complex (i.e. cause and effect were more difficult to understand), action was less noticeable.

When perceived threats and actions are summed-up using the typology presented, a pattern emerges: as a group, farmers primarily acted on simple threats to safety, where cause and effect were easy to discern (e.g. risk of fireàbuy fire extinguisher; broken seat beltàreplace seat belt), and where the threat primarily affected them personally (Fig. 3).

How does one explain the finding that overall, farmers were more likely to take adaptive actions when the threats were general, personal, and simple? With regard to general threats, the EPPM informs us that when a perceived threat is strong enough to arouse fear, the individual is motivated to protect themselves if the linear combination of their selfefficacy and response efficacy are greater than the response cost. In the context of 'general' threats, this means threats that are common to most farms. Because of this, these threats are more likely to have proven solutions that are effective - the response efficacy is high. At the same time and for similar reasons, the ability to manage general safety threats, such as faulty wiring or a broken seat belt, are easier due to their routine occurrence. It could be expected that context specific

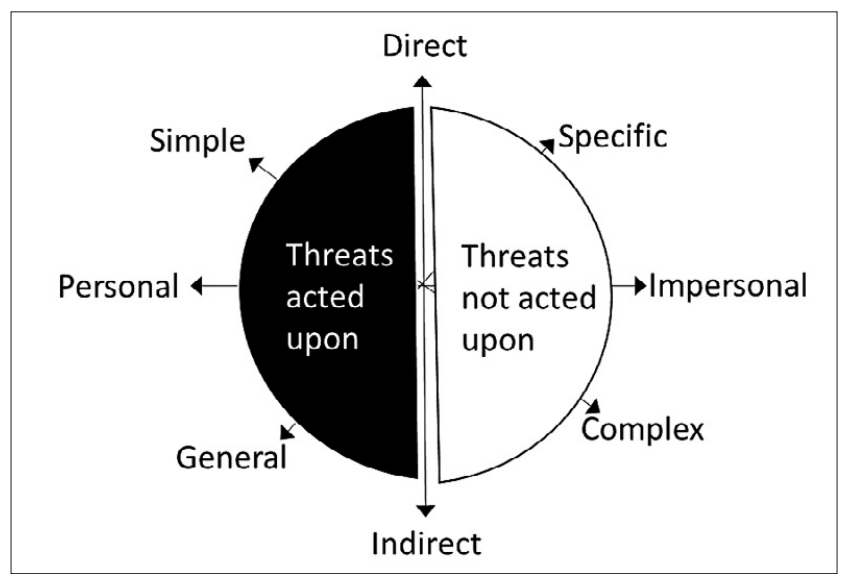

Figure 3. Typology of threats and disconnect between perceived threats and actions taken by the farmers

threats have solutions that are less well defined, and which decrease the perception of response efficacy. At the same time, because of their specificity, there are fewer people to turn to for help in managing the threat in these cases which, in turn, lowers self-efficacy.

Threats that are 'simple' by nature have causes that are easy for farmers to identify and effects that are known. This makes it more likely that simple threats are identified and farmers will understand what will happen if adaptive action is not taken. The opposite is arguably true for complex threats, that is, they are harder to identify and in many cases have multiple causes. For example, most of the parents feared for their children being injured on the farm; however, the underlying reasons for what will cause their injury were so complex that most of them did not know how to respond. If they secured a tractor wheel, the children would play with the hay bales; if the hay bales were secured, the children would move on to the next most dangerous object. Parents would 'try harder' to keep an eye on the children, but it never removed the complex threat of injury. In lieu of effective responses to this complex threat, many of them maladapted by turning a blind eye or blaming inadequacies in their safe work education.

As discussed in the Results, there was a disconnection between the safety threats at work that farmers feared most and the actions they took to remove the threats. This was most obvious when threats were distinguished by their personalimpersonal nature. Farmers especially feared threats to others/impersonal, yet spent most of their time taking action to remove threats of a personal nature. EPPM offers a simple explanation for this peculiar finding: first, farmers indicated over and over that they lacked the ability to influence 'others'; elderly parents simply refused to follow safety requests, children being children were impossible to monitor at all times, while farm hands were either too unreliable or too sophomoric to understand safety instructions. The inability to control 'others' is an indication of low self-efficacy and a prime explanation for the lack of safety adoption.

\section{DISCUSSION}

The purpose of this study was to identify threats farmers perceive related to their occupational safety, and to understand how they cognitively process and respond to them. However, before discussing the implications of the study, several 
limitations have to be stressed. The findings in this study are based on qualitative interviews with a sample that may not reflect the views of farmers in other parts of the world, let alone those in northern Sweden. It follows, therefore, that the types of risks identified and strategies for reducing risks may look very different in other countries; for example, agriculture in Scania is known for its efficient production of commodity products that is driven by innovation. As such, the machinery operate and the pressure the farmers are under ensure low cost-high output, and places them under considerable stress that other, possibly more traditional farmers, do not face. Moreover, only farmers who had previously participated in a work safety intervention were interviewed. Without a control group, it was not possible know to what extent their risk perceptions and related cognitions are related to the specific intervention, or if they are reflective of other farmers who did not participate in an intervention. This said, the authors believe that the approach taken offered several advantages. Traditionally the EPPM model is used to isolate a specific threat followed by an analysis on the cognitive mediation surrounding the threat and subsequent behaviour $[44,45$, $46,47,48,49,50]$. Because semi-structured interviews were used [55], in order to explore work safety behaviour and the EPPM as a theoretical lens, several insights were gained into the range and complexity of perceived threats, cognitive mediation and subsequent behaviour that were not possible using more traditional methods.

The threats farmers perceive encompassed a wider spectrum than previous research has addressed $[5,7,8,23$, $33,45,59]$. Just by looking at the most serious/likely perceived threats (i.e. those that can be expected to arouse fear), it was found that they can be divided into four categories:

1) perceived threats that are indirect and personal;

2) threats that are direct and personal;

3) threats that are indirect and related to others;

4) threats that are direct and related to others.

At the same time, perceived threats that were unlikely to arouse fear were also identified (i.e. those perceived as either less serious and/or less likely to occur). Interestingly, several of these non-fear arousing threats were those communicated to farmers in work safety intervention programmes [12, 14]. For example, the threat of fire (and subsequent need for a fire blanket and extinguisher) was seen as unlikely and not very serious, despite being one of the standard intervention behaviours promoted in, e.g. 'Safe Farmers Common Sense' [60]. These findings are interesting for improving safe work interventions in Sweden because they shift the focus from direct, personal threats, to threats that are indirect and include others. For example, although it has long been known that threats involving children arouse fear, and can motivate individuals to take action $[61,62,63,64]$, and threats that are both indirect and direct regarding employees seem to be as motivating as direct, personal threats. Future intervention programmes should consider conveying some of these threats in order to motivate adaptive behaviours.

Identifying efficacious responses to threats are more important than the threats that precede them [12]. The second research question posed by the authors sought to understand which actions farmers perceived to be effective, manageable, and cost effective in reducing threats to safety $[19,20]$. The EPPM suggests that fear arousal combined with low efficacy actions (i.e. response efficacy and self-efficacy) motivates individuals to maladapt or enter into the fear control process $[16,65]$. It was found that many of the strategies needed to reduce threats were accompanied by perceptions of high self-efficacy but low response efficacy $[6,19,20,66]$. There was also a discrepancy between the work safety actions farmers took and the types of threats that aroused fear. Of the threat-reducing behaviours farmers pursued, most dealt with personal threats of a direct nature. This was surprising in the light of the farmers expressing threats to others as the threats causing them the greatest concern.

Why, then, did the farmers in this study engage more frequently in behaviours that reduced personal threats, but were of less concern than threats to others $[67,68]$ ? The EPPM does not provide theoretical guidance in answering this question. However, the authors argue that the typology created in this study combined with EPPM provides several compelling explanations. By parsing threats into simple/ complex, general/simple, direct/indirect and personal/ impersonal, a number of patterns began to emerge. For example, the threats that farmers took action to reduce were (almost) exclusively specific, simple, and personal in nature $[47,50]$. As the threat became more complex, selfefficacy decreased [42]; as the threat became more general, understanding the cause also became more difficult, thereby reducing response efficacy, but when the threats were impersonal, the farmers lacked self-efficacy or the ability to control the situation. As EPPM reminds us, the existence of fears coupled with low efficacy often leads to maladaptive behaviours [21, 22, 50, 65].

Previous research has argued that work safety interventions have traditionally achieved poor results in influencing safer work environments $[5,6,7,8]$, however, on this point, the authors found contradictory evidence. On the one hand, all farmers seemed to be aware of the most common threats in their environment, and almost all of them made at least some changes to their work safety environment (crediting the intervention that took place one year previously). In this way, the interventions appeared to work in terms of generating awareness and stimulating adaptive behaviours. On the other hand, many of the same farmers who made adaptive changes also showed clear signs of maladaptation. They were aware of threats (e.g. their child getting hurt; stress; father 'working himself to death'); but instead of removing them, they exhibited strategies to lower their fear. For example, some tasks deemed too dangerous were performed by farmers and restricted to workers and others the farmer cared about. By doing this, they managed the source of fear (e.g. a work hand being injured), but not the actual danger. As occupational health and safety culture, in part, is modelled by the behaviour of owners and managers, and it may be the case that their maladaptive behaviours are learned vicariously by others $[69,70,71,72]$. Consequently, this may be increasing 'resilience' or 'adaption to danger despite risk' in the next generation of farmers [73]. Thus, in relation to these threats, the intervention succeeded in elevating awareness and arousing fear, but failed to achieve the more important objective of a safer working environment.

\section{CONCLUSIONS}

These findings do not tell us if the intervention followed up on in this study or similar interventions employing fear 
appeals do more good than harm. However, they raise several important questions and opportunities for future research. For example, should work safety interventions try to reduce all threats, or perhaps those very complex threats that are difficult to manage? Should they instead only focus on a subset of the most common or most dangerous or simple threats? In aiming too broadly or at those that are too complex, safety interventions risk generating fear without providing threat reduction strategies that are credible or manageable. This creates conditions where farmers are motivated to manage their fear rather than manage safety risks. Conceivably, this may lead to situations where maladaptive behaviours become contagious, e.g. 'no matter how many changes I make, in the end, farming is still dangerous, so what is the point"); the farmer simply disengages from work safety information and improvement processes [71], and goal disengagement. Alternatively, limiting interventions to very specific threats, such as those that are simple, common or present extreme danger [4], would make it easier to find strategies that are manageable and credible, and perhaps reduce the likelihood of maladaptive behaviour. On the surface, this seems like a safer approach to intervention; however, most farmers are already aware of the most common and dangerous threats $[1,4,69,70]$ and if they are simple enough to understand, the farmers in our sample tended to take actions to avoid them without needing intervention.

Fear appeals can motivate attitude and behaviour changes, together with high efficacy messages $[19,23,34]$; this makes them an attractive tool for work safety interventions. However, fear appeals should be used with care, since they may promote adaptive as well as maladaptive behaviours. The authors believe there is a need for rethinking how the "effectiveness" of interventions are viewed. Even if interventions are successful in reducing some injuries, they may very well be missing a golden opportunity to reduce a wider range of work safety risks that are too 'complex', 'general', or 'indirect'. Using the typology created for this study would be the first step in understanding the complexity of risks that exist, and in the next step developing strategies for their reduction.

\section{Acknowledgment}

We thank the Scania farmers for their willingness to participate in this study and The Royal Swedish Academy of Agriculture and Forestry (KSLA) that made this work possible through the research project (H142-0024-SLO).

\section{REFERENCES}

1. Donham M, Thelin A. Agricultural Medicine: Rural Occupational and Environmental Health, Safety and Prevention. 2nd ed. John Wiley \& Sons; 2016; ISBN: 978-1-118-64720-2.

2. Jadhav R, Achutan C, Haynatzki G, Rajaram S, Rautiainen R. Review and meta-analysis of emerging risk factors for agricultural injury. J Agromed. 2016; 21(3): 284-297.

3. Eurostat. Agriculture, forestry, and fishery statistics. Luxembourg: European Statistical Office. 2017. Retrieved from http://ec.europa.eu/ eurostat/web/products-statistical-books/-/KS-FK-17-001

4. Pinzke S, Alwall Svennefelt C, Lundqvist P. Occupational injuries in Swedish agriculture-development and Preventive actions. 2018.

5. Holte KA, Follo G. Making occupational health and safety training relevant for farmers: evaluation of an introductory course in occupational health and safety in Norway. Safety Sci. 2018; 109: 368-376.

6. Witte K. Putting the fear back into fear appeals: the extended parallel process model. Communications Monographs. 1992; 59(4): 329-349. doi:10.1080/03637759209376276
7. Rautiainen R, Lehtola MM, Day LM, Schonstein E, Suutarinen J, Salminen S, Verbeek JH. Interventions for preventing injuries in the agricultural industry. The Cochrane Library; 2008.

8. Marlenga B, Berg RL, Pickett W. National public health data systems in the United States: applications to child agricultural injury surveillance. J Rural Health; 2018.

9. Sorensen JA, May JJ, Paap K, Purschwitz MA, Emmelin M. Encouraging farmers to retrofit tractors: a qualitative analysis of risk pe, rceptions among a group of high-risk farmers in New York. J Agric Safety Health 2008; 14(1): 105-117.

10. Stave C, Törner M, Eklöf M. An intervention method for occupational safety in farming-evaluation of the effect and process. Appl Ergon. 2007; 38(3): 357-368.

11. Caffaro F, Lundqvist P, Cremasco MM, Göransson E, Pinzke S, Nilsson K, Cavallo E. Falls from Tractors in Older Age: Risky Behaviours in a Group of Swedish and Italian Farmers Over 65. In Congress of the International Ergonomics Association, 2018; (pp. 78-86). Springer, Cham.

12. Alwall Svennefelt C, Hunter E, Lundqvist P. Evaluating the Swedish approach to motivating improved work safety conditions on farms: insights from fear appeals and the extended parallel processing model. J Agromed. 2018; 23(4): 355-373.

13. Tan-Wilhelm D, Witte K, Liu WY, et al. Impact of a worker notification program: assessment of attitudinal and behavioural outcomes. View Issue TOC. 2000; 37: 205-213.

14. Smith SW, Rosenman KD, Kotowski MR, et al. Using the EPPM to create and evaluate the effectiveness of brochures to increase the use of hearing protection in farmers and landscape workers. J Appl Commun Res. 2008; 36(2):200-218. doi:10.1080/00909880801922862.

15. Tebeaux E. Safety warnings in tractor operation Manuals, 19201980: manuals and warnings don't always work. J Technical Writing Communication. 2010; 40(1):3-28. doi:10.2190/TW.40.1.b.

16. Witte Kim, Allen M. A meta-analysis of fear appeals: implications for effective public health campaigns. Health Education Behaviour 2000; 27(5): 591-615.

17. De Hoog N, Stroebe W, De Wit J. The impact of vulnerability to and severity of a health risk on processing and acceptance of fear-arousing communications: A meta-analysis. Rev General Psychol. 2007; 11(3): 258.

18. Tannenbaum MB, Hepler J, Zimmerman RS, Saul L, Jacobs S, Wilson K, Albarracín D. Appealing to fear: A meta-analysis of fear appeal effectiveness and theories. Psychol Bulletin 2015; 141(6): 117820.

19. Rogers RW. A protection motivation theory of fear appeals and attitude changel. J Psychol. 1975; 91(1): 93-114.

20. Rogers RW. Cognitive and psychological processes in fear appeals and attitude change: A revised theory of protection motivation. Social psychophysiology: A sourcebook, 1983; 153-176.

21. Berkowitz L, Cottingham, DR. The interest value and relevance of fear arousing communications. J Abnormal Social Psychol. 1960; 60(1): 37.

22. Brehm JW. A theory of psychological reactance. 1966.

23. Witte K, Peterson, TR, Vallabhan S, Stephenson MT, Plugge CD, Givens VK, Jarrett R. Preventing tractor-related injuries and deaths in rural populations: Using a persuasive health message framework in formative evaluation research. Int Q Community Health Educ. 1992; 13(3): 219-251.

24. Lindahl C, Lundqvist P, Hagevoort GR, et al. Safety aspects of animal handling in dairy production. J Agromedicine. 2013; 18:274-283. doi:10.1080/ 1059924X.2013.796906.

25. Baksh K, Ganpat W, Narine, L. Farmers knowledge, attitudes and perceptions of occupational health and safety hazards in Trinidad, West Indies and implications for the Agriculture sector. J Agric Extension Rural Dev. 2015; 7(7): 221-228.

26. Biener L, Harris JE, Hamilton W. Impact of the Massachusetts tobacco control programme: population based trend analysis. BMJ 2000; 321(7257): 351-354.

27. Donovan RJ, Jalleh G, Henley N. Executing effective road safety advertising: are big production budgets necessary? Accident Analysis Prevention 1999; 31(3): 243-252.

28. Grey M, Boland EA, Davidson M, Li J, Tamborlane WV. Coping skills training for youth with diabetes mellitus has long-lasting effects on metabolic control and quality of life. J Pediatrics, 2000; 137(1): 107-113.

29. Hagel LM, Pickett W, Pahwa P, Day L, Brison RJ, Marlenga B, Dosman JA. Prevention of agricultural injuries: an evaluation of an educationbased intervention. Inj Prev. 2008; 14(5): 290-295.

30. Laberge M, MacEachen E, Calvet B. Why are occupational health and safety training approaches not effective? Understanding young worker learning processes using an ergonomic lens. Safety Sci. 2014; 68: 250-257. 
31. DeRoo LA, Rautiainen RH. A systematic review of farm safety interventions. Am J Prev Med. 2000; 18(4): 51-62. doi:10.1016/S07493797(00)00141-0.

32. Frick CM RTW, Reigeluth CM. Formative research: A methodology for creating and improving design theories. Instructional-design theories and models, 1999; 2 .

33. Whitman SD, Field WE. Assessing senior farmers' perceptions of tractor and machinery-related hazards. 1995.

34. Dillard JP. Rethinking the study of fear appeals: An emotional perspective. Communication Theory, 1994; 4(4): 295-323.

35. Hovland CI, Janis IL, Kelly HH. Communication and persuasion; psychological studies of opinion change. 1953.

36. Maddux JE, Rogers RW. Protection motivation and self-efficacy: a revised theory of fear appeals and attitude change. J Exp Soc Psychol. 1982; 19:469-479. doi:10.1016/0022-1031(83)90023-9.

37. Leventhal H. Findings and theory in the study of fear communications. Adv Exp Soc Psychol. 1970; 5, pp. 119-186.

38. Popova L. The extended parallel process model illuminating the gaps in research. Health Education Behaviour. Sage J. 2012; 39(4):455-473.

39. Bandura A. Self-efficacy: toward a unifying theory of behavioural change. Psychol Rev. 1977; 84(2): 191.

40. Leventhal H. Fear appeals and persuasion: the differentiation of a motivational construct. Am J Public Health. 1971; 61: 6, pp. 1208-1224.

41. Maloney Erin K, Lapinski MK, Witte K. Fear appeals and persuasion: A review and update of the extended parallel process model. Soc Personality Psychol Com., 2011; 5(4): 206-219.

42. Witte, K. Preventing teen pregnancy through persuasive communications: realities, myths, and the hard-fact truths. J Com Health. 1997; 22(2): 137-154.

43. Rimal RN. Perceived risk and self-efficacy as motivators: Understanding individuals' long-term use of health information. J Commun. 2001; 51(4): 633-654.

44. Witte K. A theory of cognition and negative affect: extending Gudykunst and Hammer's theory of uncertainty and anxiety reduction. Int J Intercultural Relations. 1993; 17: 197-215. doi:10.1016/0147-1767(93) 90025-410.1016/0147-1767(93)90025-4.

45. Ambe F, Murphy DJ. Injury prevention programming for aged tractor operators. J Agric Saf Health. 1995; 1(2): 105-116. doi:10.13031/2013.19458.

46. McMahan S, Witte K, Meyer JA. The perception of risk messages regarding electromagnetic fields: extending the extended parallel process model to an unknown risk. Health Commun, 1998; 10(3): 247-259.

47. Rimal R. Perceived risk and self-efficacy as motivators: understanding individuals' long-term use of health information. J Commun. 2001; 51(4): 633-654. doi:10.1111/j.1460-2466.2001.tb02900.x.

48. Lewis I, Watson B, White KM. Extending the explanatory utility of the EPPM beyond fear-based persuasion. Health Commun. 2013; 28(1): 84-98.

49. Ralston RA. Motivation activation and the EPPM: Exploring realtime fear appeal processing (Doctoral dissertation, The Ohio State University). 2016.

50. Maloney EK, Lapinski MK, Witte K. Fear appeals and persuasion: a review and update of the extended parallel process model. Soc Personal Psychol Compass. 2011; 5(4):206-219. doi:10.1111/spco.2011.5.issue-4.

51. Hine DW, Phillips WJ, Reser JP, Cooksey RW, Marks ADG, Nunn PD, Ellul M. Enhancing climate change communication: strategies for profiling and targeting Australian interpretive communities. Gold
Coast, Australia: National Climate Change Adaptation Research Facility. 2013; p. 95.

52. Hine DW, Phillips WJ, Cooksey R, Reser JP, Nunn P, Marks AD,Watt SE. Preaching to different choirs: How to motivate dismissive, uncommitted, and alarmed audiences to adapt to climate change? Global Environ Change. 2016; 36: 1-11.

53. Turnbull N, Algie J. A qualitative analysis of young drivers' perceptions of driver distraction social marketing interventions. 2015.

54. Cismaru M, Nimegeers K. Keep your eyes up, don't text and drive: a review of anti-texting while driving Campaigns' recommendations. Inter Rev Public Nonprofit Marketing. 2017; 14(1): 113-135.

55. Kvale S, Brinkmann S. Interview: introduktion til et håndværk. Hans Reitzel. 2009.

56. Bryman, A. Social research methods. Oxford university press. 2016.

57. Braun V, Clarke V. Using thematic analysis in psychology. Q Res Psychol. 2006; 3(2): 77-101.

58. Guest G, Namey EE, Mitchell ML. Collecting qualitative data: A field manual for applied research. 2012; Sage.

59. Morgan SE, Cole HP, Struttmann T, Piercy L. Stories or statistics? Farmers' attitudes toward messages in an agricultural safety campaign. J Agric Safety Health, 2002; 8(2): 225.

60. Danielson (Ed.). Säkert Bondförnuft. Slutrapport för projektet 2009-2013. (Safe farmers common sense. A final 515 report for the project 2009-2013) (In Swedish). Swedish Farmers Federation (LRF). Stockholm. 2013.

61. Lee B, Marlenga B. Professional resource manual: North American guidelines for children's agricultural tasks. Marshfield, WI: Marshfield Clinic. 1999.

62. Klassen TP, MacKay JM, Moher D, Walker A, Jones AL. Communitybased injury prevention interventions. Future Child. 2000; 83-110.

63. Gadomski A, Ackerman S, Burdick P, Jenkins P. Efficacy of the North American guidelines for children's agricultural tasks in reducing childhood agricultural injuries. Am J Public Health 2006; 96(4): $722-727$.

64. Nilsson K. Parents' attitudes to risk and injury to children and young people on farms. PLoS one, 2016; 11(6): e0158368.

65. Witte K. Fear as motivator, fear as inhibitor: Using the extended parallel process model to explain fear appeal successes and failures. In: Handbook of communication and emotion. 1996; p. 423-450.

66. Beck KH, Frankel A. A conceptualization of threat communications and protective health behaviour. Soc Psychol Q. 1981; 204-217.

67. Weinstein ND. Unrealistic optimism about susceptibility to health problems. J Behav Med. 1982; 5(4): 441-460.

68. Weinstein ND. Unrealistic optimism about future life events. J Personal Soc Psychol. 1980; 39(5): 806.

69. Lunner Kolstrup C, Kallioniemi M, Lundqvist P, Kymäläinen, HR, Stallones L, Brumby S. International perspectives on psychosocial working conditions, mental health, and stress of dairy farm operators. J Agromed. 2013; 18(3): 244-255.

70. Nilsson K, Pinzke S, Lundqvist P. Occupational injuries to senior farmers in Sweden. J Agric Safety Health. 2010; 16(1): 19-29.

71. Wrosch C, Scheier, MF, Carver CS, Schulz R. The importance of goal disengagement in adaptive self-regulation: When giving up is beneficial. Self Identity 2013; 2(1): 1-20.

72. Bandura, A. Vicarious processes: A case of no-trial learning. Adv Exp Soc Psychol. 1965; 2: 1-55). Academic Press.

73. Arrington EG, Wilson MN. A re-examination of risk and resilience during adolescence: Incorporating culture and diversity. J Child Family Stud. 2000; 9(2): 221-230.

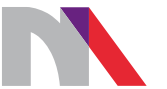

Ministry of Science and Higher Education

Republic of Poland

Generation of the DOI (Digital Object Identifier) - task financed under the agreement No. 618/P-DUN/2019 by the Minister of Science and Higher Education 